\title{
Indications and technical details of sublobar resections for small-sized lung cancers based on tumor characteristics
}

\author{
Hirohisa Kato, Hiroyuki Oizumi, Jun Suzuki, Katsuyuki Suzuki, Satoshi Takamori \\ Department of Surgery 2, Faculty of Medicine, Yamagata University, Yamagata 990-9585, Japan.
}

Correspondence to: Dr. Hirohisa Kato, Department of Surgery 2, Faculty of Medicine, Yamagata University, 2-2-2 lida-Nishi, Yamagata 990-9585, Japan. E-mail: h-kato@med.id.yamagata-u.ac.jp

How to cite this article: Kato H, Oizumi H, Suzuki J, Suzuki K, Takamori S. Indications and technical details of sublobar resections for small-sized lung cancers based on tumor characteristics. Mini-invasive Surg 2021;5:5.

http://dx.doi.org/10.20517/2574-1225.2020.98

Received: 7 Oct 2020 First Decision: 27 Nov 2020 Revised: 24 Dec 2020 Accepted: 19 Jan 2021 Published: 3 Feb 2021

Academic Editors: Alan D.L. Sihoe, Noriyoshi Sawabata Copy Editor: Xi-Jun Chen Production Editor: Yue-Yue Zhang

\begin{abstract}
With the recent increase in small-sized lung cancers, sublobar resection and minimally invasive surgeries are becoming preferred. In particular, the detection of ground-glass nodules (GGNs) on high-resolution computed tomography has increased. Although lobectomy has been considered a standard procedure for treating lung cancer, sublobar resections have been indicated for treating GGN-dominant small-sized lung cancers. Wedge resection and segmentectomy have generally been performed as sublobar resection; however, each procedure has some technical advantages and disadvantages. Although anatomical resection as a segmentectomy is a complicated procedure, it has recently been increasingly performed with the accurate anatomical grasp using three-dimensional computed tomography and the identification of the intersegmental plane. Other procedures involving the use of newer technologies can also be performed. Individualized sublobar resection might be a suitable procedure for small-sized lung cancer with the appropriate selection of procedures based on each tumor's characteristics and improving the methods to overcome some technical difficulties.
\end{abstract}

Keywords: Sublobar resection, ground-glass nodule, wedge resection, segmentectomy, subsegmentectomy, thoracoscopic surgery \footnotetext{
CC) (7) (c) The Author(s) 2021. Open Access This article is licensed under a Creative Commons Attribution 4.0 sharing, adaptation, distribution and reproduction in any medium or format, for any purpose, even commercially, as long as you give appropriate credit to the original author(s) and the source, provide a link to the Creative Commons license, and indicate if changes were made.
} 


\section{INTRODUCTION}

On the basis of a study by Ginsberg et al ${ }^{[1]}$, it has been considered that lobectomy is the standard procedure for lung cancer treatment. However, more than 20 years have passed since this evidence was reported, and the concept may be inappropriate for small-sized lung cancers in the present era. Recently, the number of detectable small-sized tumors has been increasing owing to the widespread use of computed tomography (CT). It has been reported that prognosis is good if the tumor has a ground-glass opacity (GGO). In their report, Ginsberg et al. ${ }^{[1]}$ did not adequately consider the characteristics of ground-glass nodules. Noguchi et al. ${ }^{[2]}$ reported that wedge resection for small, non-small cell lung cancers (NSCLCs) with GGO has been associated with favorable outcomes.

Moreover, most GGO-dominant lung nodules are adenocarcinoma in situ (AIS) or minimally invasive adenocarcinoma, which has a good pathological prognosis ${ }^{[3,4]}$. Therefore, the trend of surgical procedures for small-sized GGO-dominant lung nodules has changed from lobectomy to sublobar resection. According to the annual reports from the Japanese Association of Thoracic Surgery, the number of sublobar resections for lung cancer during 2013 to 2017 gradually increased from $23.7 \%$ to $27 \%{ }^{[5-9]}$. Among sublobar resections, wedge resection and anatomical sublobar resections (e.g., segmentectomy) have become widely performed for lung cancers owing to recent technological advancements.

This article aims to describe the indications, methods, problems, and improvements of sublobar resections for small-sized GGO-dominant lung cancers based on the recent literature. We also describe our recent experience with sublobar resections and prospects for future procedures regarding sublobar resections for small-sized lung cancers.

\section{INDICATIONS FOR SUBLOBAR RESECTION}

Many reports have compared the use of sublobar resection and lobectomy in small-sized lung cancers, especially those less than $2.0 \mathrm{~cm}$ in diameter ${ }^{[10-13]}$. A randomized trial for peripheral small-sized lung cancer $<2.0 \mathrm{~cm}$ in diameter, with or without GGO components such as CALBG 140503 and JCOG0802/ WJOG4607L, is currently in progress, and the superiority of sublobar resections is expected to be $\operatorname{proven}^{[14,15]}$.

The prognosis of small-sized GGO-dominant lung cancers is generally good ${ }^{[3,4]}$. Yano et al ${ }^{[16]}$ reported that patients with small-sized GGO-dominant lung cancers were good candidates for limited wedge resection and segmentectomy. Among tumor characteristics seen on CT, tumor size and GGO ratio are important factors for the indications of sublobar resection. Asamura et al..$^{[4]}$ reported that tumors $<2 \mathrm{~cm}$ in diameter with a GGO ratio $>75 \%$ on radiography were pathologically non-invasive. Nakata et al ${ }^{[17]}$ indicated that patients with GGO ratios $>50 \%$ should be considered candidates for sublobar resection, although those with a GGO ratio of 50\% exhibited vessel infiltration and experienced local recurrence after wedge resection. Recently, Sagawa et al ${ }^{[18]}$ reported that lung cancer patients with a GGO ratio of $>80 \%$ were good candidates for sublobar resection.

On the basis of these reports, we have indicated sublobar resection for indeterminate lung nodules in our institution when tumor characteristics meet the following criteria, to strictly secure oncological outcomes: (1) a tumor size $<2 \mathrm{~cm}$; and (2) a GGO ratio $>80 \%$. Moreover, sublobar resection has also been indicated for patients whose heart and pulmonary functions are compromised to preserve pulmonary function ${ }^{[19]}$. In other words, sublobar resection is indicated for the following two types: (1) an intentional curative resection for small-sized GGO-dominant lung cancer; and (2) a palliative resection for compromised patients with whom lobectomy is intolerable due to poor pulmonary function. 


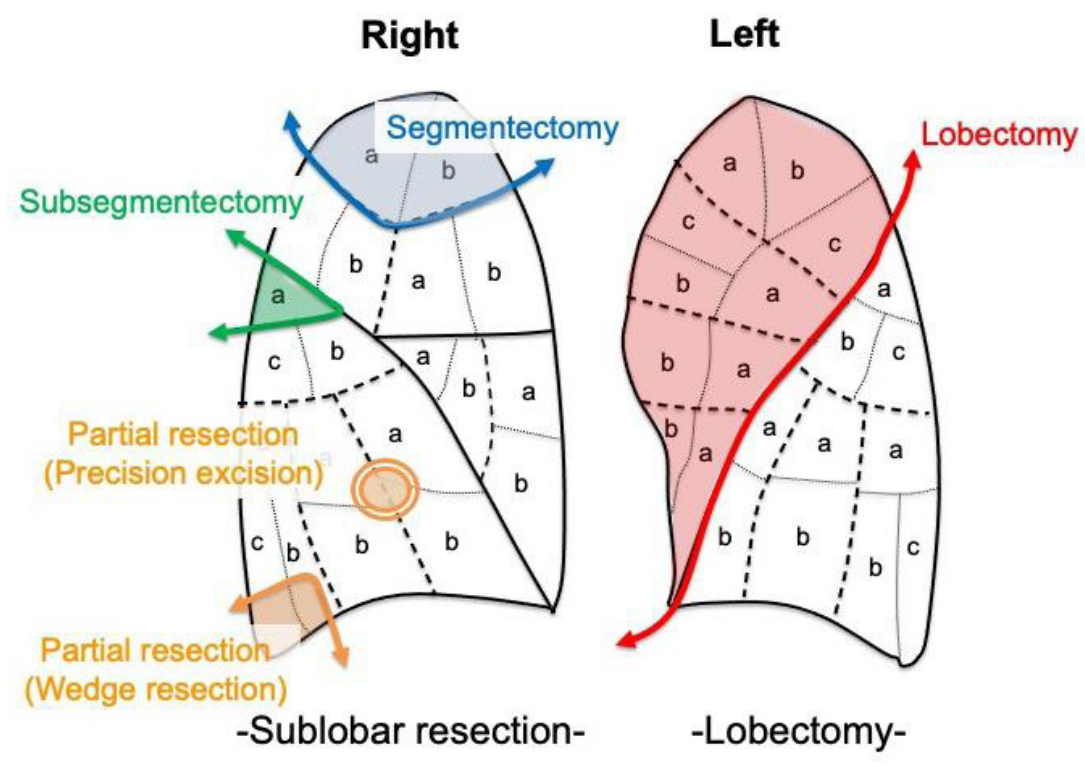

Figure 1. Procedure types for lung cancer. Although lobectomy is a standard procedure, sublobar resections such as segmentectomy, subsegmentectomy, and partial resections have also been performed in the treatment of small-sized lung cancer.

On the other hand, if sublobar resection is acceptable for small-sized lung nodules, a thoracoscopic approach is highly desirable as a minimally invasive surgery. The thoracoscopic approach has better outcomes than thoracotomy in maintaining patients' quality of life and preventing complications. It is preferred over thoracotomy because of its advantages of decreased postoperative pain, shortened chest tube duration, shortened length of hospital stay, faster return to preoperative activity levels, and preserved pulmonary function ${ }^{[20,21]}$. Therefore, thoracoscopic sublobar resection is in great demand as a minimally invasive surgical procedure.

\section{TYPES OF SUBLOBAR RESECTIONS AND THE TECHNICAL ASPECTS OF EACH PROCEDURE}

Although lobectomy has been traditionally performed as a standard procedure in many patients with lung cancer, sublobar resections have also been performed according to each patient's preoperative condition [Figure 1]. Among sublobar resections, wedge resection and segmentectomy have generally been performed for small-sized lung cancer treatments. Wedge resection has been widely performed to diagnose indeterminate lung nodules or to cure small-sized GGO-dominant lung tumors, as the procedure is not complicated ${ }^{[22]}$. Although segmentectomy is generally thought to be more complicated than wedge resection, the oncological outcomes of segmentectomy in a propensity-matched study were comparable to those of lobectomy for patients with early-stage NSCLC ${ }^{[1]}$. Therefore, segmentectomy has been advocated as an alternative procedure for lobectomy in recent years ${ }^{[10]}$.

In addition to wedge resection and segmentectomy, other procedures such as subsegmentectomy have also been performed, although not as commonly as wedge resection and segmentectomy.

Subsegmentectomy is a more minute anatomical procedure than segmentectomy, and it is indicated for smaller GGO-dominant lung cancers in which a sufficient surgical margin can be secured. In this procedure, it is necessary to understand more peripheral anatomical structures ${ }^{[23]}$. If the tumor size is small and the GGO component ratio large, and if a sufficient surgical margin can be secured, subsegmentectomy can be accepted as a procedure among sublobar resections because the number of reports on the procedure has increased recently ${ }^{[2,25]}$. Another characteristic of subsegmentectomy is that it has the advantage 
of securing better surgical margins by segmentectomy combined with adjacent subsegmentectomy if segmentectomy alone cannot secure sufficient surgical margins.

Perelman first described the traditional precision excision method; it is somewhat similar to wedge resection but involves the non-use of some staplers and the use of electrocautery to secure a sufficient surgical margin ${ }^{[26]}$. This method has the following advantages: (1) maximum conservation of lung tissue in limited resection for deep-seated lesions; (2) minimal deformity or damage to the adjacent lung tissue; and (3) ability to obtain the maximum margin of tissue around lesions ${ }^{[27]}$. A large wedge resection using a stapler might cause a large deformation; in such cases, this method can be advantageous. In particular, when the tumor is superficial on a flat surface, such as interlobar in hilum site or at the bottom of the lower lobe, this method might be useful, as wedge resection using a stapler might be impossible to perform due to a thick parenchyma.

While segmentectomy and subsegmentectomy are anatomical resections, wedge resection and precision excision are non-anatomical resections. There are some advantages and disadvantages to anatomical resections because it is necessary to dissect the hilar area. While lymph node metastasis can be evaluated via lymph node dissection, severe adhesion of the hilum can occur after surgery. Therefore, in cases where cancer recurs and a second surgery is needed after the first surgery, it is assumed that performing a second surgery is difficult due to severe adhesions. On the other hand, although non-anatomical resections have an advantage in that adhesion of the hilum is less likely to occur, it is challenging to evaluate lymph node metastasis. Therefore, non-anatomical resections might be appropriate for cases that do not require evaluation of lymph node metastasis. Thus, there are conflicting differences between anatomical and nonanatomical resections. Careful selection of these procedures must be performed by considering the future clinical course of each patient.

Generally, the decision between anatomical resection as segmentectomy and non-anatomical resection as wedge resection depends on the tumor location in small-sized lung cancer. For example, Doo et al. ${ }^{[28]}$ reported that wedge resection would be difficult for tumors located $>20 \mathrm{~mm}$ from the pleural surface. Suzuki et al ${ }^{[29]}$ suggested that the probability of nodule detection failure is high for tumors located $>5$ $\mathrm{mm}$ from the pleural surface and for tumors $<10 \mathrm{~mm}$ in diameter. In sublobar resection techniques, it is important to secure sufficient surgical margins from targeted tumors ${ }^{[30]}$. The surgical margins are assumed to be more limited in wedge resection than in segmentectomy because wedge resection for tumors deeply located from the pleural surface makes it difficult to secure an adequate surgical margin. Mohiuddin et al. ${ }^{[31]}$ reported that the margin distance in wedge resection for small non-small cell carcinoma affects local recurrence and that increasing the margin distance significantly decreases the local recurrence risk. The selection of these procedures should be considered to secure sufficient surgical margins based on tumor characteristics, such as tumor location, size, and depth from the pleural surface. However, the types of sublobar resection remain controversial ${ }^{[32]}$. The selection of sublobar resections may differ in each institution because each procedure has its own respective advantages and disadvantages for a precise resection that can secure a sufficient surgical margin.

\section{TECHNICAL PROBLEMS OF SUBLOBAR RESECTIONS}

\section{Localization of a small-sized tumor during wedge resection}

Although wedge resection is a simple procedure, precise resection of the targeted tumor is challenging when the tumor location is undetectable. For example, when the tumor is located deep within the parenchyma, tumor detection is complicated because these tumors are not easily visualized or palpated by the surgeon's finger under thoracoscopy. Therefore, the localization and identification of small-sized GGO lung tumors during thoracoscopic surgery is challenging, and various methods have been reported ${ }^{[33-36]}$. The standard traditional method using a CT-guided hook wire involves the risk of complications such as 


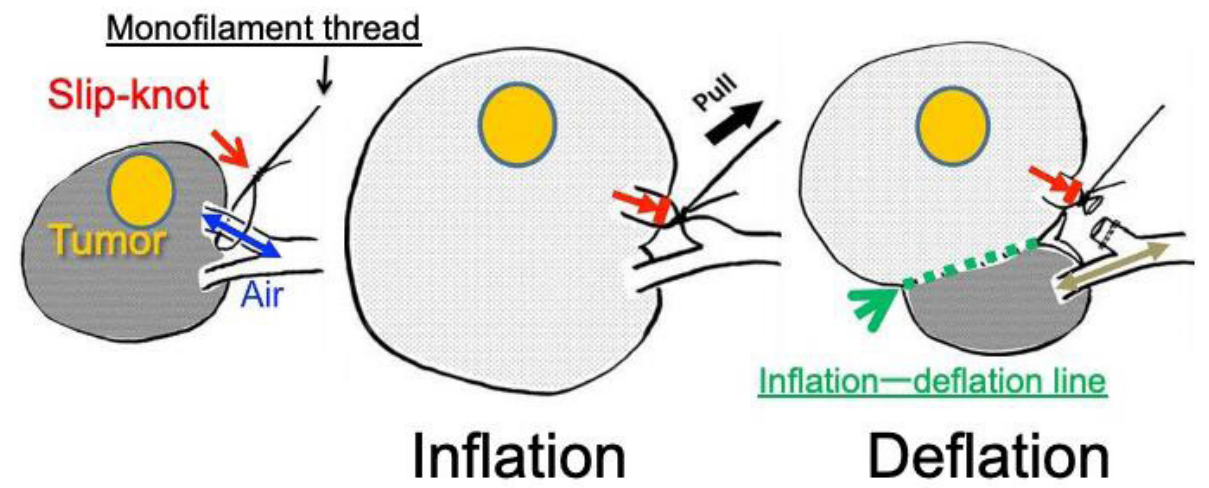

Figure 2. Slip-knot technique. The slip-knot made with a monofilament thread is fully pulled to ligate the targeted segmental bronchus after bilateral lung ventilation. The affected segment remains inflated, while adjacent segments appear collapsed. The targeted segmental bronchus is then divided with a stapler.

pneumothorax, hematoma, and air embolism ${ }^{[37,38]}$. Therefore, to avoid these complications, the development of alternative methods has been discussed in recent years.

\section{Identification of intersegmental planes in segmentectomy}

In segmentectomy and subsegmentectomy, it is essential to understand the precise anatomy of the patient's bronchus and pulmonary vessels. To precisely understand the anatomic structure of the pulmonary vessels and bronchus, three-dimensional (3D) CT reconstruction is used. There are many reports on the understanding of anatomical structures using a $3 \mathrm{D}$ reconstruction tool ${ }^{[39-41]}$. The critical process of segmentectomy and subsegmentectomy is ensuring the intersegmental plane and the intersubsegmental plane while dividing the parenchyma along the intersegmental and intersubsegmental lines. Although the inflation-deflation line using jet ventilation is a traditional method used to ensure the intersegmental plane and the intersubsegmental planes ${ }^{[42]}$, its disadvantages include lack of technical skills for performing bronchoscopy by anesthesiologists, use of jet ventilation, and difficulty in patients with emphysematous lung. Accordingly, other methods for visualizing the intersegmental plane (selective dye injection into the segmental bronchus using a needle) have been reported ${ }^{[43]}$. Although this technique may be accessible in open thoracotomy, it is difficult to complete during thoracoscopic surgery. To perform segmentectomy thoracoscopically, we have improved thoracoscopic segmentectomy using the following simplified technique: the slip-knot technique for creating an intersegmental plane [Figure 2$]^{[44]}$. The essential device of this technique is simply a slip-knot made by a monofilament thread, and the essential process is merely pulling of the slip-knot. Therefore, this method is simpler, easier, and less expensive than any other conventional method. In our institution, air insufflation through a targeted segmental bronchus incision has recently been performed [Figure 3]. We believe this technique is simple and useful.

\section{RECENT TECHNICAL IMPROVEMENTS IN THORACOSCOPIC SUBLOBAR RESECTIONS}

\section{Localization methods for small-sized tumors in wedge resection}

In the localization method of wedge resection for targeted tumors, Gill et al ${ }^{[45]}$ conducted a prospective clinical trial of image-guided video-assisted thoracoscopic surgery (iVATS), in which percutaneous markings are created with two T-bars utilizing intraoperative C-arm CT. In this study, the targeted tumor was successfully resected with no intraoperative complications. In recent years, the number of iVATS methods has increased due to the introduction of $\mathrm{C}$-arm CT in many institutions ${ }^{[46,47]}$. This method, which is advantageous without serious complications, was also introduced to our institution. Moreover, the most recent technology is the marking method in which the area near the tumor is marked using a wireless marking system (The radiofrequency identification system, Hogy Medical Co, Ltd, Tokyo, Japan) ${ }^{[48]}$. This method is a transbronchial approach using bronchoscopy and can reduce complications such as air 

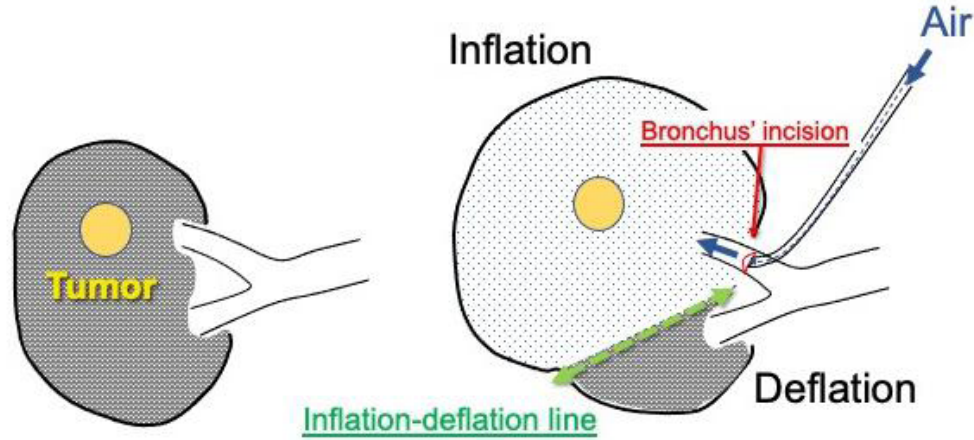

Figure 3. The targeted segmental bronchus incision is made to inflate the affected segment by air insufflation.

embolism by avoiding parenchymal puncture. Although these methods depend on the equipment of every institution, it is expected that an iVATS method or a wireless marking system will become a significant method of tumor identification in the future.

\section{Identification methods for intersegmental planes in segmentectomy}

For visualization and division of the intersegmental plane in segmentectomy, a new thoracoscopy detection method involving the use of indocyanine green has become increasingly popular ${ }^{[49-51]}$. Furthermore, Sato et al. ${ }^{[52]}$ reported that the VAL-MAP method, which can secure sufficient surgical margins using the dye around the tumor before segmentectomy, has been growing increasingly popular in Japan. Regarding the 3D reconstruction of pulmonary vessels and the bronchus, there is an improvement in $3 \mathrm{D}-\mathrm{CT}$ and anatomical reconstruction progression in $3 \mathrm{D}$ models' references using $3 \mathrm{D}$ printers ${ }^{[53]}$. These improvements have assisted in the performance of various types of thoracoscopic segmentectomies.

\section{THORACOSCOPIC SUBLOBAR RESECTIONS BASED ON INDICATION CRITERIA FROM OUR INSTITUTION AND PROSPECTS FOR SUBLOBAR RESECTION}

Based on the above description, we performed sublobar resections for patients who meet the following criteria: (1) non-solid lung tumor with planned resection of a cT1aNoMo primary lung cancer, $<2 \mathrm{~cm}$ in diameter, with a GGO ratio $>80 \%$, as determined by high-resolution CT in patients with good pulmonary function and who can tolerate lobectomy; and (2) limited cardiopulmonary reserve or organ failure in compromised patients who are considered poor candidates for lobectomy. Regarding the approach, thoracoscopic sublobar resection was indicated whenever we thought it was possible. Our thoracoscopic surgical strategy for small-sized lung nodules is shown in Figure 4.

In September 2015, we introduced a hook wire method under general anesthesia using C-arm CT to avoid complications such as air embolism [Figure 5A and B]. To prevent air embolism, CT-guided lung biopsy under breath-holding and hook wire localization after exhalation has been reported because negative intrathoracic pressure is assumed to be associated with atmospheric air aspiration into the pulmonary vasculature ${ }^{[54-56]}$. We applied the hook wire method based on the assumption that air embolism might occur under spontaneous breathing but not at the end of the exhalation phase because it is assumed that breathholding might be easier to manage under general anesthesia. We performed wedge resection using this method in 16 cases; serious complications such as air embolism did not occur during the procedure. The precision excision method has been performed in approximately 20 cases since 2009 [Figure 6A-C]. In this method, we used an energy device to divide the parenchyma in addition to electrocautery, and the energy device was useful in the control of bleeding and air leakage during the surgery. This method was indicated for cases in which tumor resection using a stapler was expected to be inappropriate due to the tumor's 


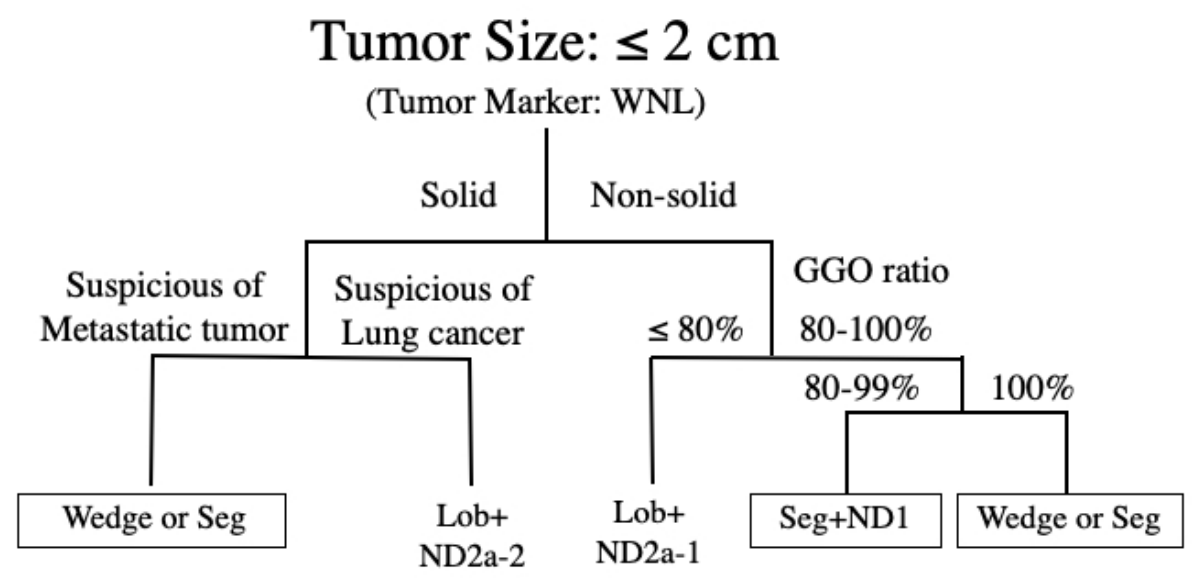

Figure 4. Thoracoscopic surgical strategy for a small-sized lung tumor in our institute. WNL: Within normal limit; GGO: ground-glass opacity; Wedge: wedge resection; Lob: lobectomy; Seg: segmentectomy; ND: nodal dissection.
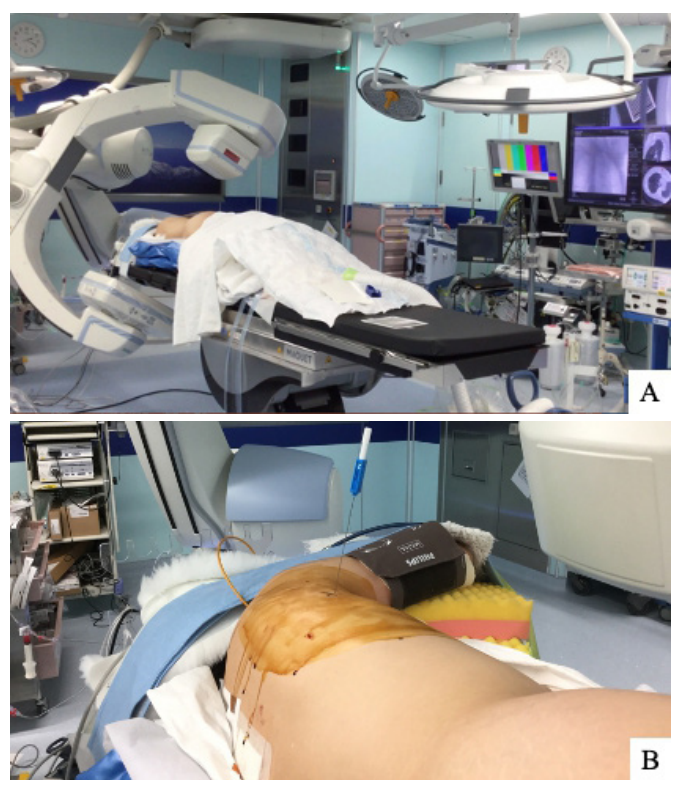

Figure 5. Current tumor marking method: A hook wire placement is performed under general anesthesia in a hybrid operating room. After the patient was intubated with a double-lumen tube under general anesthesia, the targeted tumor was identified using C-arm CT (A). A hook wire was then inserted near the targeted tumor, referring to the CT image (B). After tumor marking, the targeted tumor was resected via wedge resection.
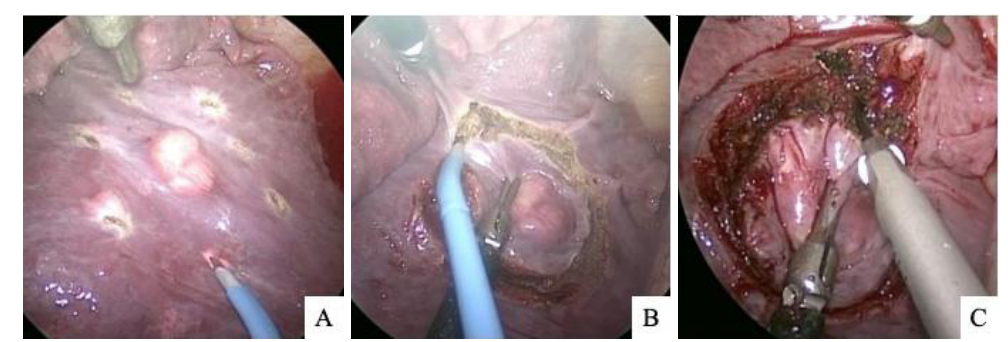

Figure 6. Precision excision method for small-sized tumors. First, some markings were performed around the targeted tumor using electrocautery (A). Second, the visceral parenchyma was divided with a sufficient surgical margin using electrocautery (B). Finally, the parenchyma was divided using an energy device, and the targeted tumor was resected (C). 

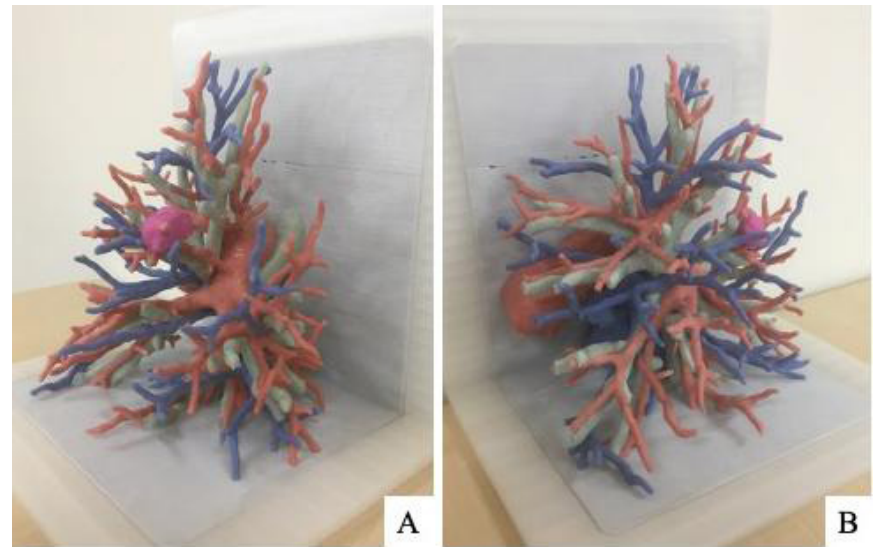

Figure 7. A three-dimensional model of the pulmonary vessels and bronchus was made using a three-dimensional printer. The pink color represents the targeted tumor, the white color represents the bronchi, the red color represents the pulmonary arteries, and the blue color represents the pulmonary veins.

location. The surgical margins were sufficiently secured, and there were no recurrences.

Recently, we introduced a wireless marking method for the treatment of indeterminate lung nodules ${ }^{[48]}$. Three patients underwent wedge resection after marking. In all cases, the tumors were completely resected, and one patient was diagnosed with AIS. Although the number of cases is still small, we believe that these methods are useful for tumor identification in wedge resection.

From July 2004 to August 2020, thoracoscopic segmentectomy and subsegmentectomy for lung cancer were performed using 3D-CT simulation in 366 patients. Segmentectomy was done in 247 cases, subsegmentectomy in 69 cases, and segmentectomy combined with adjacent subsegmentectomy in 50 cases. We applied 3D-CT simulation and the slip-knot technique for these anatomical sublobar resections. First, the parenchyma was dissected using an energy device from the hilar site to the peripheral site along the intersegmental veins. Following the division of the segmental artery and vein, the segmental bronchus was dissected, and an inflation-deflation line was created ${ }^{[4]}$. The inflation-deflation line can be gradually identified as the intersegmental line. The bronchus was then divided with a stapler or ligated with a silk thread based on the bronchial diameter. The parenchyma was then dissected along the intersegmental veins and the inflation-deflation lines using either an electrocautery or an energy device, and the venous branches running into the affected segment were divided. Finally, the peripheral parenchyma was divided using a stapler. With these techniques, our thoracoscopic segmentectomy and subsegmentectomy procedures secured sufficient surgical margins and were thoroughly improved. The outcomes of thoracoscopic segmentectomy and subsegmentectomy were excellent, and there were no recurrences in intentional cases on the basis of our criteria of sublobar resections, although a small number of compromised cases were known to have recurrences. Thus, we performed thoracoscopic sublobar resections for small-sized lung cancers using these methods, and the outcomes were satisfactory in terms of curative operation. Although we have mainly indicated sublobar resection in GGO-dominant tumors, this procedure might also be indicated in small-sized solid tumors less than $2.0 \mathrm{~cm}$ in diameter because previous studies have reported favorable outcomes ${ }^{[10-15]}$.

In recent years, we have referred to a 3D model of the pulmonary vessels and bronchus before and during surgery [Figure 7A and B]. The model is useful for understanding the precise anatomy of each patient. We prepared this model mainly for anatomical sublobar resections in patients with whom tumor localization is expected to be difficult. Moreover, reports on the single-port approach have been increasing. We also began various types of segmentectomies using this approach and investigated its safety and feasibility. 
Furthermore, minimally invasive surgery has progressed in robotic surgery. Robotic surgery is more suitable for small spaces, such as the pelvic cavity. A small working space is sufficient to perform sublobar resections. A new style robot system such as a da Vinci SP may be effectively used for sublobar resections as a minimally invasive surgical procedure in the future.

The selection of procedures for sublobar resection must be adapted to each patient according to tumor size, GGO ratio, and tumor location. Individualized sublobar resection will continue to evolve with applications such as CT and other new methods.

In conclusion, thoracoscopic sublobar resection might be a suitable procedure for small-sized lung cancers with the appropriate selection of procedures based on each tumor's characteristics and methods described herein and will continue to be further improved with new technologies in the future.

\section{DECLARATIONS}

\section{Authors' contributions}

Substantial contributions to the conception and design of the study: Kato H, Oizumi H, Suzuki J, Suzuki K, Takamori S

\section{Availability of data and materials}

Not applicable.

\section{Financial support and sponsorship}

None.

\section{Conflicts of interest}

All authors declared that there are no conflicts of interest.

\section{Ethical approval and consent to participate}

Not applicable.

\section{Consent for publication}

Not applicable.

\section{Copyright}

(c) The Author(s) 2021.

\section{REFERENCES}

1. Ginsberg RJ, Rubinstein LV. Randomized trial of lobectomy versus limited resection for T1 N0 non-small cell lung cancer. Ann Thorac Surg 1995;60:615-23.

2. Noguchi M, Morikawa A, Kawasaki M, et al. Small adenocarcinoma of the lung. Histologic characteristics and prognosis. Cancer 1995; $75: 2844-52$

3. Travis WD, Brambilla E, Noguchi M, et al. International association for the study of lung cancer/american thoracic society/european respiratory society international multidisciplinary classification of lung adenocarcinoma. J Thorac Oncol 2011;6:244-85.

4. Asamura H, Hishida T, Suzuki K, et al. Radiographically determined noninvasive adenocarcinoma of the lung: survival outcomes of Japan Clinical Oncology Group 0201. J Thorac Cardiovasc Surg 2013;146:24-30.

5. Masuda M, Kuwano H, Okumura M, et al; Committee for Scientific Affairs, The Japanese Association for Thoracic Surgery. Thoracic and cardiovascular surgery in Japan during 2013: annual report by The Japanese Association for Thoracic Surgery. Gen Thorac Cardiovasc Surg 2015;63:670-701.

6. Masuda M, Okumura M, Doki Y, et al; Committee for Scientific Affairs, The Japanese Association for Thoracic Surgery. Thoracic and cardiovascular surgery in Japan during 2014: annual report by The Japanese Association for Thoracic Surgery. Gen Thorac Cardiovasc Surg 2016;64:665-97. 
7. Masuda M, Endo S, Natsugoe S, et al; Committee for Scientific Affairs, The Japanese Association for Thoracic Surgery. Thoracic and cardiovascular surgery in Japan during 2015: annual report by The Japanese Association for Thoracic Surgery. Gen Thorac Cardiovasc Surg 2018;66:581-615.

8. Shimizu H, Endo S, Natsugoe S, et al; Committee for Scientific Affairs, The Japanese Association for Thoracic Surgery. Thoracic and cardiovascular surgery in Japan in 2016 : annual report by The Japanese Association for Thoracic Surgery. Gen Thorac Cardiovasc Surg 2019;67:377-411.

9. Shimizu H, Okada M, Tangoku A, et al; Committee for Scientific Affairs, The Japanese Association for Thoracic Surgery. Thoracic and cardiovascular surgeries in Japan during 2017: annual report by the Japanese Association for Thoracic Surgery. Gen Thorac Cardiovasc Surg 2020;68:414-49.

10. Okada M, Koike T, Higashiyama M, Yamato Y, Kodama K, Tsubota N. Radical sublobar resection for small-sized non-small cell lung cancer: a multicenter study. J Thorac Cardiovasc Surg 2006;132:769-75.

11. Hwang Y, Kang CH, Kim HS, Jeon JH, Park IK, Kim YT. Comparison of thoracoscopic segmentectomy and thoracoscopic lobectomy on the patients with non-small cell lung cancer: a propensity score matching study. Eur J Cardiothorac Surg 2015;48:273-8.

12. Flores R, Taioli E, Yankelevitz DF, et al. Initiative for early lung cancer research on treatment: development of study design and pilot implementation. J Thorac Oncol 2018;13:946-57.

13. Zeng W, Zhang W, Zhang J, et al. Systematic review and meta-analysis of video-assisted thoracoscopic surgery segmentectomy versus lobectomy for stage I non-small cell lung cancer. World J Surg Oncol 2020;18:44.

14. Schuchert MJ, Abbas G, Pennathur A, et al. Sublobar resection for early-stage lung cancer. Semin Thorac Cardiovasc Surg 2010;22:2231.

15. Nakamura K, Saji H, Nakajima R, et al. A phase III randomized trial of lobectomy versus limited resection for small-sized peripheral nonsmall cell lung cancer (JCOG0802/WJOG4607L). Jpn J Clin Oncol 2010;40:271-4.

16. Yano M, Yoshida J, Koike T, et al; Japanese Association for Chest Surgery. Survival of 1737 lobectomy-tolerable patients who underwent limited resection for cStage IA non-small-cell lung cancer. Eur J Cardiothorac Surg 2015;47:135-42.

17. Nakata M, Sawada S, Yamashita M, et al. Objective radiologic analysis of ground-glass opacity aimed at curative limited resection for small peripheral non-small cell lung cancer. J Thorac Cardiovasc Surg 2005;129:1226-31.

18. Sagawa M, Oizumi H, Suzuki H, et al. A prospective 5-year follow-up study after limited resection for lung cancer with ground-glass opacity. Eur J Cardiothorac Surg 2018;53:849-56.

19. Harada H, Okada M, Sakamoto T, Matsuoka H, Tsubota N. Functional advantage after radical segmentectomy versus lobectomy for lung cancer. Ann Thorac Surg 2005;80:2041-5.

20. Kaseda S, Aoki T, Hangai N, Shimizu K. Better pulmonary function and prognosis with video-assisted thoracic surgery than with thoracotomy. Ann Thorac Surg 2000;70:1644-6.

21. Atkins BZ, Harpole DH Jr, Mangum JH, Toloza EM, D’Amico TA, Burfeind WR Jr. Pulmonary segmentectomy by thoracotomy or thoracoscopy: reduced hospital length of stay with a minimally-invasive approach. Ann Thorac Surg 2007;84:1107-12; discussion 1112-3.

22. Nakayama H, Yamada K, Saito H, et al. Sublobar resection for patients with peripheral small adenocarcinomas of the lung: surgical outcome is associated with features on computed tomographic imaging. Ann Thorac Surg 2007;84:1675-9.

23. Kato H, Oizumi H, Inoue T, et al. Port-access thoracoscopic anatomical lung subsegmentectomy. Interact Cardiovasc Thorac Surg 2013;16:824-9.

24. Li C, Han Y, Han D, et al. Robotic approach to combined anatomic pulmonary subsegmentectomy: technical aspects and early results. Ann Thorac Surg 2019;107:1480-6.

25. Chang CC, Yen YT, Lin CY, Chen YY, Huang WL, Tseng YL. Single-port video-assisted thoracoscopic surgery subsegmentectomy: the learning curve and initial outcome. Asian J Surg 2020;43:625-32.

26. Perel'man MI. A precision technic of removing pathological structures from the lungs. Khirurgiia (Mosk) 1983;12-4.

27. Cooper JD, Perelman M, Todd TR, Ginsberg RJ, Patterson GA, Pearson FG. Precision Cautery Excision of Pulmonary Lesions. Ann Thorac Surg 1986;41:51-3.

28. Doo KW, Yong HS, Kim HK, Kim S, Kang EY, Choi YH. Needlescopic resection of small and superficial pulmonary nodule after computed tomographic fluoroscopy-guided dual localization with radiotracer and hookwire. Ann Surg Oncol 2015;22:331-7.

29. Suzuki K, Nagai K, Yoshida J, et al. Video-assisted thoracoscopic surgery for small indeterminate pulmonary nodules: indications for preoperative marking. Chest 1999;115:563-8.

30. Sawabata N. Locoregional recurrence after pulmonary sublobar resection of non-small cell lung cancer: can it be reduced by considering cancer cells at the surgical margin? Gen Thorac Cardiovasc Surg 2013;61:9-16.

31. Mohiuddin K, Haneuse S, Sofer T, et al. Relationship between margin distance and local recurrence among patients undergoing wedge resection for small ( $\leq 2 \mathrm{~cm}$ ) non-small cell lung cancer. J Thorac Cardiovasc Surg 2014;147:1169-75; discussion 1175-7.

32. Kato H, Oizumi H, Suzuki J, et al. What is the most appropriate procedure for intraoperative localization of small pulmonary nodules? $J$ Thorac Dis 2018;10:E155-7.

33. Mack MJ, Gordon MJ, Postma TW, et al. Percutaneous localization of pulmonary nodules for thoracoscopic lung resection. Ann Thorac Surg 1992;53:1123-4.

34. Bolton WD, Howe H 3rd, Stephenson JE. The utility of electromagnetic navigational bronchoscopy as a localization tool for robotic resection of small pulmonary nodules. Ann Thorac Surg 2014;98:471-5; discussion 475-6.

35. Mack MJ, Shennib H, Landreneau RJ, Hazelrigg SR. Techniques for localization of pulmonary nodules for thoracoscopic resection. $J$ Thorac Cardiovasc Sur 1993;106:550-3. 
36. Ikeda K, Nomori H, Mori T, et al. Impalpable pulmonary nodules with ground-glass opacity: Success for making pathologic sections with preoperative marking by lipiodol. Chest 2007;131:502-6.

37. Ciriaco P, Negri G, Puglisi A, Nicoletti R, Del Maschio A, Zannini P. Video-assisted thoracoscopic surgery for pulmonary nodules: rationale for preoperative computed tomography-guided hookwire localization. Eur J Cardiothorac Surg 2004;25:429-33.

38. Horan TA, Pinheiro PM, Araújo LM, Santiago FF, Rodrigues MR. Massive gas embolism during pulmonary nodule hook wire localization. Ann Thorac Surg 2002;73:1647-9.

39. Oizumi H, Kanauchi N, Kato H, et al. Anatomic thoracoscopic pulmonary segmentectomy under 3-dimensional multidetector computed tomography simulation: a report of 52 consecutive cases. J Thorac Cardiovasc Surg 2011;141:678-82.

40. Iwano S, Yokoi K, Taniguchi T, Kawaguchi K, Fukui T, Naganawa S. Planning of segmentectomy using three-dimensional computed tomography angiography with a virtual safety margin: technique and initial experience. Lung Cancer 2013;81:410-5.

41. Xue L, Fan H, Shi W, et al. Preoperative 3-dimensional computed tomography lung simulation before video-assisted thoracoscopic anatomic segmentectomy for ground glass opacity in lung. J Thorac Dis 2018;10:6598-605.

42. Okada M, Mimura T, Ikegaki J, Katoh H, Itoh H, Tsubota N. A novel video-assisted anatomic segmentectomy technique: selective segmental inflation via bronchofiberoptic jet followed by cautery cutting. J Thorac Cardiovasc Surg 2007;133:753-8.

43. Zhang Z, Liao Y, Ai B, Liu C. Methylene blue staining: a new technique for identifying intersegmental planes in anatomic segmentectomy. Ann Thorac Surg 2015;99:238-42.

44. Oizumi H, Kato H, Endoh M, Inoue T, Watarai H, Sadahiro M. Slip knot bronchial ligation method for thoracoscopic lung segmentectomy. Ann Thorac Surg 2014;97:1456-8.

45. Gill RR, Zheng Y, Barlow JS, et al. Image-guided video assisted thoracoscopic surgery (iVATS) - phase I-II clinical trial. J Surg Oncol 2015;112:18-25.

46. Rouzé S, de Latour B, Flécher E, et al. Small pulmonary nodule localization with cone beam computed tomography during video-assisted thoracic surgery: a feasibility study. Interact Cardiovasc Thorac Surg 2016;22:705-11.

47. Hsieh MJ, Wen CT, Fang HY, Wen YW, Lin CC, Chao YK. Learning curve of image-guided video-assisted thoracoscopic surgery for small pulmonary nodules: A prospective analysis of 30 initial patients. J Thorac Cardiovasc Surg 2018;155:1825-32.

48. Yutaka Y, Sato T, Matsushita K, et al. Three-dimensional navigation for thoracoscopic sublobar resection using a novel wireless marking system. Semin Thorac Cardiovasc Surg 2018;30:230-7.

49. Misaki N, Chang SS, Igai H, Tarumi S, Gotoh M, Yokomise H. New clinically applicable method for visualizing adjacent lung segments using an infrared thoracoscopy system. J Thorac Cardiovasc Surg 2010;140:752-6.

50. Guigard S, Triponez F, Bédat B, Vidal-Fortuny J, Licker M, Karenovics W. Usefulness of near-infrared angiography for identifying the intersegmental plane and vascular supply during video-assisted thoracoscopic segmentectomy. Interact Cardiovasc Thorac Surg 2017;25:703-9.

51. Sekine Y, Itoh T, Toyoda T, et al. Precise anatomical sublobar resection using a 3D medical image analyzer and fluorescence-guided surgery with transbronchial instillation of indocyanine green. Semin Thorac Cardiovasc Surg 2019;31:595-602.

52. Sato M, Omasa M, Chen F, et al. Use of virtual assisted lung mapping (VAL-MAP), a bronchoscopic multispot dye-marking technique using virtual images, for precise navigation of thoracoscopic sublobar lung resection. J Thorac Cardiovasc Surg 2014;147:1813-9.

53. Cheng GZ, San Jose Estepar R, Folch E, Onieva J, Gangadharan S, Majid A. Three-dimensional printing and 3D slicer: powerful tools in understanding and treating structural lung disease. Chest 2016;149:1136-42.

54. Cheng HM, Chiang KH, Chang PY, et al. Coronary artery air embolism: a potentially fatal complication of CT-guided percutaneous lung biopsy. Br J Radiol 2010;83:e83-5.

55. Marchak K, Hong MJ, Schramm KM. Systemic air embolism following CT-guided percutaneous core needle biopsy of the lung: case report and review of the literature. Semin Intervent Radiol 2019;36:68-71.

56. Ichinose J, Kohno T, Fujimori S, Harano T, Suzuki S. Efficacy and complications of computed tomography-guided hook wire localization. Ann Thorac Surg 2013;96:1203-8. 